\title{
Measurement of Spontaneous Imbibition Capillary Pressure, Saturation and Resistivity Index by Counter Current Technique at Net Reservoir Stress and Elevated Temperature.
}

\author{
Stefano Pruno ${ }^{1,}$, , Hans Erik Rodvelt ${ }^{1}$, Ola Skjæveland ${ }^{1}$ \\ ${ }^{1}$ Weatherford Laboratories (Norway) AS, Stavanger
}

\begin{abstract}
Capillary pressure and resistivity index spontaneous imbibition experiments by the porous plate method, in a core holder at elevated temperature and net reservoir stress, are both difficult and time consuming special core analysis measurements to perform. In this type of experiment, low capillary forces act against a low permeable porous plate and only one face of the cylindrical core sample is in capillary contact with the fluid saturated porous plate. In this paper, core samples having different lithology, petrophysical properties and wettability are analysed by counter current spontaneous imbibition, starting at initial water saturation (Swi), at net confining pressure and elevated temperature. Synthetic brine is used as the wetting phase and Isopar L mineral oil as the non-wetting phase. This methodology is applied to investigate and evaluate how to obtain more reliable, more efficient and faster saturation imbibition data combined with electrical measurements, during spontaneous imbibition measurements. Resistivity index (RI), saturation exponent (n) (by single saturation equilibrium point using Archie's second law RI= Sw-n) and wettability information using representative fluids, confining pressure and temperature are also obtained by applying this specific counter current imbibition technique and improved procedural approach.
\end{abstract}

\section{Introduction}

Spontaneous imbibition is an important recovery mechanism and can occur in either co-current or countercurrent modes. This is mainly a capillary pressure dominated process, in which the rate of imbibition is controlled by the rock petrophysical properties and lithology, fluids type (interfacial tension, composition and properties) and interaction between them at representative pressure and temperature conditions. Capillary pressure causes formation brine to invade into a rock sample containing oil or gas at initial water saturation and distribution. Wettability is one of the most important parameters during this process, as it controls the microscopic displacement efficiency and distribution of the different fluids within the rock pore system. Traditionally, wettability tests are based on the combination of the Amott and USBM methods. These measurements are routinely performed at the end of the primary drainage cycle using standard Amott glass cells at ambient pressure. The test may be performed at elevated temperature, dependent upon the fluid system involved. However, certain core properties such as poor degree of consolidation and core process constraints (e.g. maintaining confining pressure throughout the whole experimental analysis, evaporation and limitation in electrical measurements capability) require analyses of the spontaneous capillary cycle to be performed at net confining pressure. This negates the use of Amott cells; in this case an alternative special core analysis method must be employed. Counter-current recovery is one such process, where a strongly wetting phase (water) displaces a non-wetting phase spontaneously under the influence of capillary forces such that the non-wetting phase moves in the opposite direction to the water. The sample is loaded into an electrically insulated core holder during the whole experiment and should remain in the core holder at representative pressure and temperature conditions throughout the spontaneous capillary imbibition process. This methodology allows additional wettability information derived from formation resistivity index data and complex impedance measurements to be obtained. The main challenge is to accurately collect and register oil production with time. Normally capillary pressure and resistivity index (PcRI) spontaneous imbibition experiments in a core holder by the porous plate method are performed after the primary drainage cycle by lowering stepwise the Pc of the displacing phase (oil). This allows the displaced phase (brine) to imbibe back into the samples through the water-wet porous plate or membrane. This is a very time consuming process; in addition,

* corresponding author: Stefano.Pruno@weatherford.com

(c) The Authors, published by EDP Sciences. This is an open access article distributed under the terms of the Creative Commons Attribution License 4.0 (http://creativecommons.org/licenses/by/4.0/). 
capillary contact issues, gas diffusion and blockage could, in some cases, invalidate this experiment because the brine will not imbibe back into the rock sample. The AirMercury capillary injection technique also allows spontaneous imbibition measurements down to atmospheric pressure, but this technique has significant methodology limitations related to the fact that both representative fluids and reservoir conditions cannot be used. Our study has mainly focused on wettability, lithology, test conditions, permeability and initial water saturation, (Swi) properties. Tests of PcRI by countercurrent imbibition by low rate end face flooding have been performed on different sandstone samples (Bentheim, Berea and Parker type) and one carbonate lithology sample (Carbonate V).

\section{Experimental}

\subsection{Brine}

Synthetic formation water, (SFW) with a composition of $100,000 \mathrm{ppm} \mathrm{NaCl}$, properties are given in Table 1a. The brine was degassed by vacuum and filtered to 0.40 microns prior to use. The viscosity and the density of the brine were $0.508 \mathrm{cP}$ and $1.048 \mathrm{~g} / \mathrm{cm} 3$ at $70 \mathrm{oC}$ respectively. The brine resistivity, Rw was equal to $0.037 \mathrm{Ohm}-\mathrm{m}$ at $70 \mathrm{oC}$ and the brine $\mathrm{pH}$ was 6.9 .

\subsection{Mineral Oil}

Isopar L ${ }^{\circledR}$ of $0.595 \mathrm{cP}$ viscosity with density of 0.768 $\mathrm{g} / \mathrm{cm} 3$ at $70 \mathrm{oC}$ was used in tests as the oil phase. Polar contaminants were removed by flow through a packed column of aluminium and silica gel. Oil-Brine interfacial tension (IFT) was equal to $35 \mathrm{mN} / \mathrm{m}$. The mineral oil properties are reported in Table $1 \mathrm{~b}$.

Table 1a. Synthetic formation brine basic properties.

\begin{tabular}{|c|c|c|c|}
\hline $\begin{array}{c}\text { Temperature } \\
\left({ }^{\circ} \mathbf{C}\right)\end{array}$ & $\begin{array}{c}\text { Viscosity } \\
(\mathrm{cP})\end{array}$ & $\begin{array}{c}\text { Density } \\
\left(\mathrm{g} / \mathrm{cm}^{3}\right)\end{array}$ & $\begin{array}{c}\text { Resistivity } \\
(\boldsymbol{\Omega m})\end{array}$ \\
\hline 20 & 1.205 & 1.071 & 0.081 \\
25 & 1.091 & 1.068 & 0.073 \\
30 & 0.985 & 1.066 & 0.067 \\
40 & 0.818 & 1.062 & 0.057 \\
50 & 0.694 & 1.057 & 0.049 \\
60 & 0.597 & 1.052 & 0.043 \\
70 & 0.508 & 1.048 & 0.037 \\
\hline
\end{tabular}

Table 1b. Mineral Oil basic properties.

\begin{tabular}{|c|c|c|}
\hline $\begin{array}{c}\text { Temperature } \\
\left({ }^{\circ} \mathbf{C}\right)\end{array}$ & $\begin{array}{c}\text { Viscosity } \\
(\mathbf{c P})\end{array}$ & $\begin{array}{c}\text { Density } \\
\left(\mathrm{g} / \mathrm{cm}^{3}\right)\end{array}$ \\
\hline 20 & 1.309 & 0.759 \\
25 & 1.193 & 0.755 \\
30 & 1.092 & 0.752 \\
40 & 0.923 & 0.745 \\
50 & 0.790 & 0.737 \\
60 & 0.682 & 0.730 \\
70 & 0.595 & 0.722 \\
\hline
\end{tabular}

\subsection{Core Material}

The samples were 1.5 inch diameter plug material cored from outcrop Bentheim, Berea, Parker sandstone and a carbonate outcrop rock. Klinkenberg corrected gas permeability, KL, were between $10 \mathrm{mD}$ and $2.4 \mathrm{D}$. Ambient helium porosity ranged from 17.3 to $22.1 \%$ (see Table 2). All samples were cleaned by submerged Soxhlet extraction and dried in a convection oven at $60 \mathrm{oC}$ until stable weight was achieved. After cleaning with solvents and drying, the wettability state of the tested samples was assumed to be Strongly Water-Wet (SWW).Wettability of four samples was altered to Strongly Oil-Wet conditions (SOW), using chemical pre-treatment (Hydrophobic Silane) prior to sample saturation and the primary drainage capillary cycle. Both SWW and SOW samples were analysed. Computed tomography 3D scan samples screening, nuclear magnetic resonance (NMR) at ambient conditions ( $\mathrm{T} 1$ and $\mathrm{T} 2$ ) were performed at 100\% Sw conditions on all samples. Mercury Injection Capillary Pressure (MICP) ambient and pore throat size distribution analysis (drainage and imbibition run) was performed on selected sample end trims.

\subsection{Establishment of Initial Water Saturation}

The clean and dry cores were saturated with synthetic formation water by use of vacuum and pressure in single core holders to ensure complete saturation with brine. Resistivity measurements at full saturated conditions were performed until ionic equilibrium was achieved. Initial water saturation was established by capillary pressure primary drainage by the porous plate technique in single core holders at isostatic Net Confining Pressure (NCP) and temperature. Mineral oil was used as the displacing phase during the single step drainage cycle up to 5 bar capillary pressure. Resistivity, temperature, capillary pressure (Pc) and water saturation $(\mathrm{Sw})$ were monitored as a function of time until stability was achieved. The Pc and Swi data are presented in Table 3. The saturation uncertainty is approximately $+/-0.02$ (frac.) of pore volume (Vp) and RI accuracy is equal to $+/-2 \%$. Saturation exponent (n) uncertainty is 0.10 unit. 


\subsection{Initial Aging}

Because the mineral oil was free of aging altering components, it was assumed that the original wettability established during sample preparation was not altered. In a more standard SCAL workflow, the core samples will be prepared by a suitable cleaning procedure and wettability restoration will occur during 4 to 6 month primary crude oil/water capillary drainage cycle by porous plate, at pressure and temperature conditions, in a single core holder.

\subsection{Spontaneous Imbibition by Counter Current}

After completion of the primary drainage cycle at Swi, spontaneous capillary imbibition was performed in the same electrically insulated core holder that was used to perform the primary drainage cycle, without handling the sample, at net confining pressure and $70 \mathrm{o}$. The source for imbibition was water cycled at a low rate $(1 \mathrm{ml} / \mathrm{h})$ through the grooves (see detailed image in Figure 1) in the core holder top end piece and the produced oil was conveyed by these grooves and the upper end stem tubing to a glass visual separator. During this process both valve V1 and V3 were closed and the porous plate was still in place. Impedance, temperature, flow rate, water pressure and produced oil versus time were recorded. A schematic of the equipment setup can be found in Figure 1. The spontaneous imbibition water saturation, RI and saturation exponent (n) results are reported in Table 3.

\subsection{Final Measurements and Saturation Quality Control}

NMR T1 and T2 measurements at ambient conditions, after PcRI counter current imbibition experiments, were carried out on selected samples. Final fluids saturation quality control was performed by Dean Stark analysis, following test completion.

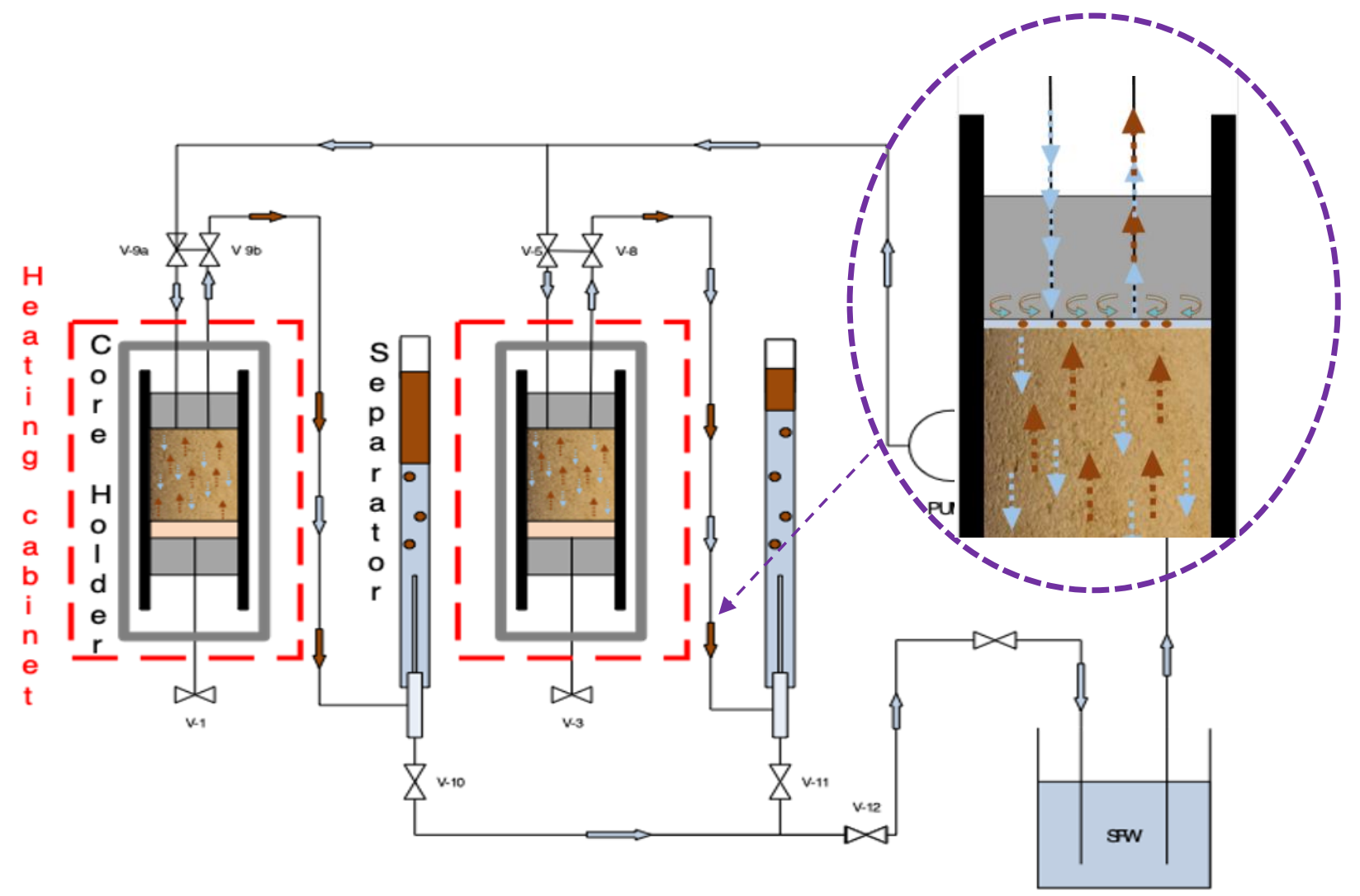

Figure 1. Experimental setup schematic for $\mathrm{P}_{c} \mathrm{RI}$ counter current spontaneous imbibition in core holder at net confining pressure and temperature conditions. 
Table 2. Core plugs base petrophysical properties.

\begin{tabular}{|c|c|c|c|c|c|c|c|}
\hline $\begin{array}{c}\text { Sample } \\
\text { No. }\end{array}$ & $\begin{array}{c}\text { Lithology } \\
\text { Type }\end{array}$ & $\begin{array}{l}\text { Length } \\
\text { (cm) }\end{array}$ & Diameter & 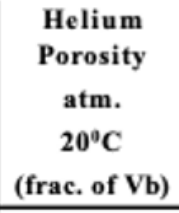 & 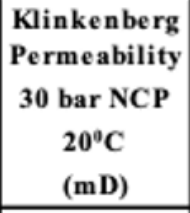 & $\begin{array}{c}\text { Grain } \\
\text { Density } \\
\text { atm. } \\
20^{\circ} \mathrm{C} \\
(\mathrm{g} / \mathrm{ml}) \\
\end{array}$ & $\begin{array}{c}\text { Wettability } \\
\text { State }\end{array}$ \\
\hline JG 6 & Bentheim sst. & 4.64 & 3.74 & 0.221 & 2350 & 2.64 & SWW \\
\hline JG 11 & Bentheim sst. & 4.51 & 3.74 & 0.221 & 2400 & 2.64 & sow \\
\hline JG 12 & Berea B sst. & 4.94 & 3.80 & 0.202 & 150 & 2.65 & SWW \\
\hline JG 17 & Berea B sst. & 3.68 & 3.79 & 0.199 & 140 & 2.66 & sow \\
\hline JG 18 & Berea B sst. & 4.91 & 3.80 & 0.199 & 120 & 2.66 & SWW \\
\hline JG 14 & Parker sst. & 3.65 & 3.79 & 0.177 & 17 & 2.67 & SWW \\
\hline JG 15 & Parker sst. & 3.72 & 3.79 & 0.178 & 18 & 2.67 & sow \\
\hline JG 19 & Parker sst. & 4.66 & 3.78 & 0.173 & 15 & 2.66 & SWW \\
\hline $\mathrm{JG} 21$ & Carbonate V & 4.01 & 3.81 & 0.177 & 10 & 2.68 & SWW \\
\hline $\mathrm{JG} 22$ & Carbonate V & 4.05 & 3.81 & 0.182 & 30 & 2.69 & sow \\
\hline
\end{tabular}

\section{Results and discussion}

A summary of residual oil saturations ( $\%$ OOIP) given by the counter-current imbibition PcRI process for the tested samples are presented in Figure 2. The figure shows the oil recovery by spontaneous water imbibition at an IFT of $35 \mathrm{mN} / \mathrm{m}$. By recording the rate of spontaneous imbibition during the counter-current experiment, a process similar to part of the Amott spontaneous imbibition of brine cycle, a good estimate of wettability can be made, also by comparison with published data [21, 22]. Spontaneous imbibition data at capillary pressure close to zero, can be used to characterize wettability in a way that reflects both rate and amount of oil production for the early time oil recovery [8,9]. Figure 4 shows the effect of rock permeability on the relationship between the imbibition rate and oil recovery. The effect of permeability on the oil recovery rate is different in different rocks; the recovery rate tends to increases with permeability for strongly water- wet samples. RI-Sw plots for each specific lithology, both water-wet and oil-wet states, are presented in Figures 5 to 8. Transient RI data can be used to assess resistivity behaviour during imbibition by counter-current technique at representative conditions. For the tested samples, capillary and resistivity imbibition experiments were conducted at two different wettability states strong water and oil-wet (SWW and SOW, Table 3). Oil-wet samples have higher initial water saturation, Swi and Archie saturation n-exponent values compared to waterwet samples. This behaviour is consistent for each specific lithology investigated (Table 3). Experimental aging time during PcRI was the same for each core. This was not relevant for our experiment, but it is known from literature that n-exponent may increase when the core is aged to more oil-wet conditions or in case of in-efficient cleaning. The data observations support this behaviour. Resistivity index versus water saturation graphs show a consistent behaviour with the wettability state of the different rock types, with higher oil saturation and n-exponent values as functions of decreasing water wetness (Figure 5 to 8). Plots of recovery by spontaneous imbibition versus logarithmic time are presented in Figure 3 for the different lithology and wettability states. Water-wet samples with higher permeability (Bentheim) show the highest oil recovery after spontaneous imbibition by the countercurrent process, followed by Carbonate V, Berea and Parker sandstone. The oil recovery in this case increases with permeability for all the three sandstone water-wet core samples. Bentheim sandstone has higher oil recovery compared to Berea and Parker. The oil recovery by spontaneous water imbibition for water-wet Bentheim, Berea and Carbonate $\mathrm{V}$ samples is greater than that in Parker sandstone samples with lower permeability. For the oil-wet samples, both Parker and Carbonate V samples showed higher recovery compared to Bentheim and Berea sandstone samples having higher permeability. The relationships between the imbibition rate and the oil recovery by spontaneous water imbibition are shown in Figure 4 . The dotted lines in these figures are the linear fits to the experimental data. The fits are good in most cases for the water-wet sandstones with different permeability. Gravity may play an important role in cases of low IFT and high permeability. In our experiment, gravity effects are assumed to be neglected due to the presence of the water wet low permeability porous plate. However, capillary pressure and fluid mobility may not be calculated independently from spontaneous imbibition capillary data if oil/water relative permeability data are not 
experimentally acquired. Dean Stark end point water saturation values after the spontaneous imbibition process at elevated temperature and pressure show good agreement for most of the tested samples and are within 3\% saturation units. Only the SOW samples have a larger discrepancy in saturation. The main reason for this specific saturation discrepancy requires further investigation. It is recommended to perform NMR (T1 and T2 relaxation time) experiments, including weight measurements and fluid saturation by Karl Fischer technique in core holder, in the case of unconsolidated/fragile lithology or presence of significant amounts of clay bound water to verify end point water saturation value. A further development for this methodology is to implement the In Situ Saturation Monitor (ISSM) technique (e.g. by gamma-ray, x-ray), data simulation and four electrode configuration resistivity method to improve control on RI accuracy and fluids saturation data and distribution respectively, during capillary spontaneous imbibition by counter-current measurements.

Table 3. Saturation and RI by counter current spontaneous imbibition results.

\begin{tabular}{|c|c|c|c|c|c|c|c|c|c|c|}
\hline $\mathbf{S} / \mathbf{N}$ & Lithology & Wett. & $\begin{array}{l}\text { KL Perm. } \\
30 \text { bar NCP } \\
20^{\circ} \mathrm{C} \\
\text { (mD) }\end{array}$ & NCP & \begin{tabular}{|} 
Initial Water \\
Saturation \\
Swi \\
NCP \\
$70^{\circ} \mathrm{C}$ \\
(frac.)
\end{tabular} & 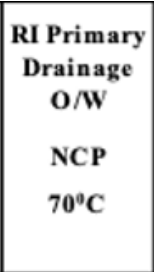 & \begin{tabular}{|c|} 
n-exp. \\
Primary \\
Drainage \\
O $/ \mathrm{W}$ \\
$\mathrm{NCP}$ \\
${70^{\circ} \mathrm{C}}$
\end{tabular} & \begin{tabular}{|c|} 
Water \\
Saturation \\
after Sp. \\
Imb. O $/ \mathrm{W}$ \\
$\mathrm{NCP}$ \\
$70^{\circ} \mathrm{C}$ \\
(frac.)
\end{tabular} & $\begin{array}{c}\text { RI CC } \\
\text { Imbibition } \\
\text { O } / \mathrm{W} \\
\mathrm{NCP} \\
{70^{\circ} \mathrm{C}}^{-}\end{array}$ & $\begin{array}{c}\text { n-exp. CC } \\
\text { Imbibition } \\
\text { O/W } \\
\text { NCP } \\
7^{\circ} \mathrm{C}\end{array}$ \\
\hline JG 6 & Bentheim sst. & SWW & 2350 & 100 & 0.067 & 101 & 1.71 & 0.656 & 4.49 & 3.57 \\
\hline JG 11 & Bentheim sst. & sow & 2400 & 100 & 0.485 & 23.0 & 4.33 & 0.516 & 21.5 & 4.76 \\
\hline JG 12 & Berea B sst. & SWW & 150 & 100 & 0.147 & 57.6 & 2.11 & 0.511 & 6.65 & 2.82 \\
\hline JG 17 & Berea B sst. & sow & 140 & 100 & 0.460 & 59.1 & 5.26 & 0.466 & 52.0 & 5.18 \\
\hline JG 18 & Berea B sst. & SWW & 120 & 100 & 0.151 & 48.1 & 2.05 & 0.647 & 5.49 & 3.91 \\
\hline JG 14 & Parker sst. & SWW & 17 & 30 & 0.269 & 18.3 & 2.21 & 0.653 & 5.17 & 3.85 \\
\hline JG 15 & Parker sst. & sow & 18 & 30 & 0.391 & 41.1 & 3.95 & 0.584 & 31.2 & 6.40 \\
\hline JG 19 & Parker sst. & SWW & 15 & 30 & 0.304 & 14.8 & 2.27 & 0.592 & 4.99 & 3.07 \\
\hline JG 21 & Carbonate V & SWW & 10 & 30 & 0.252 & 15.9 & 2.01 & 0.664 & 8.01 & 5.08 \\
\hline $\mathrm{JG} 22$ & Carbonate V & sow & 30 & 100 & 0.432 & 15.8 & 3.29 & 0.590 & 13.7 & 4.95 \\
\hline
\end{tabular}

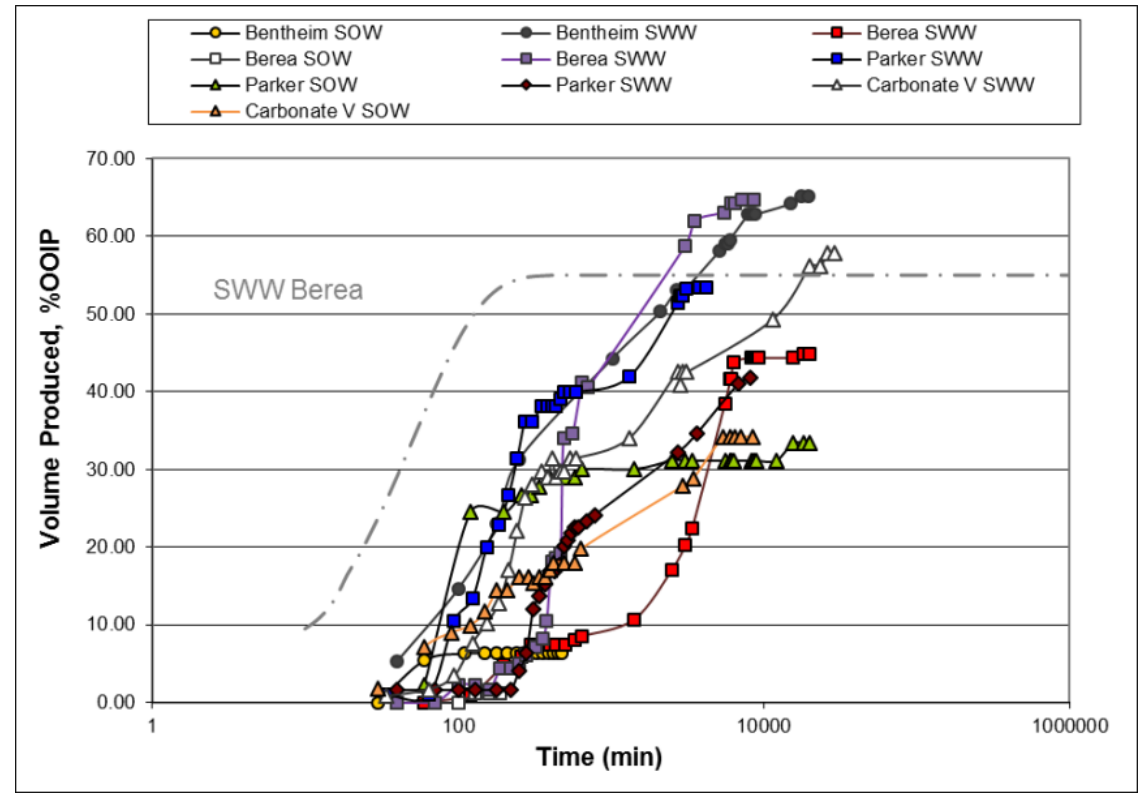

Figure 2. Rate of spontaneous imbibition of brine (Volume produced, \% OOIP) vs. time for all measured samples. 

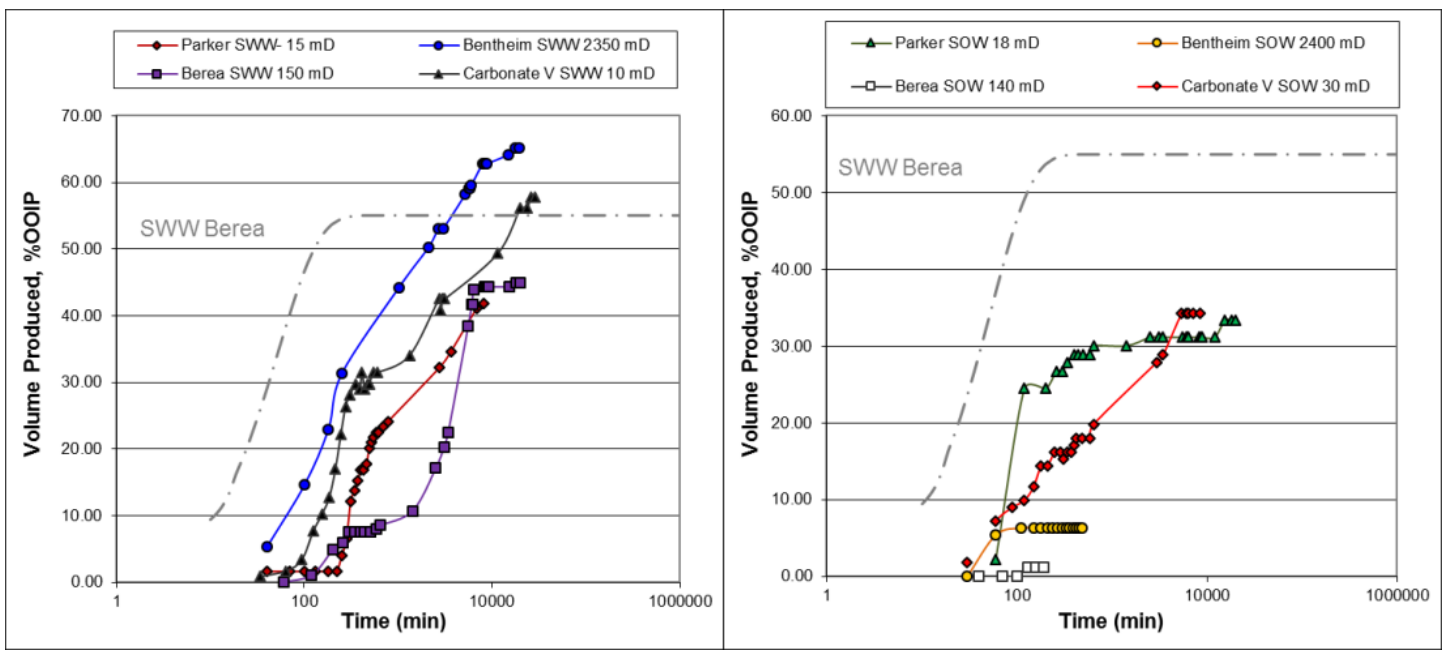

Figure 3. Rate of spontaneous imbibition of brine (Volume produced, \% OOIP) vs. time for different samples lithology and permeability, both for water and oil-wet state.

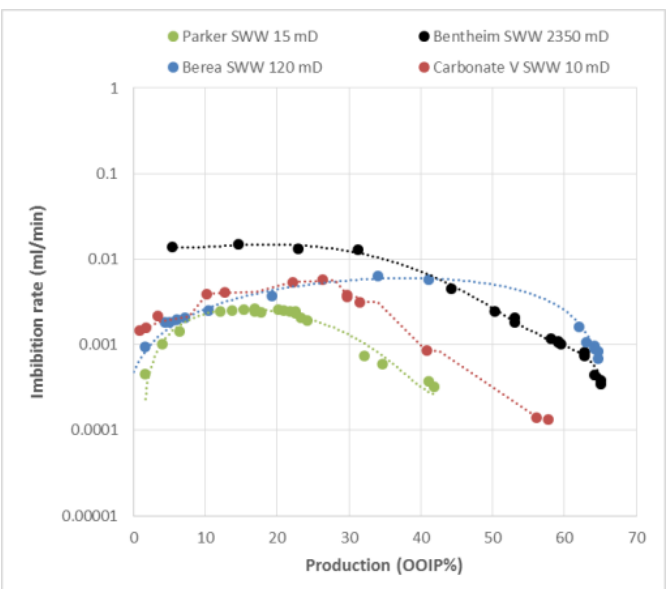

Figure 4. Imbibition rate and oil recovery (\% OOIP) for different rock types, IFT $35 \mathrm{mN} / \mathrm{m}$.
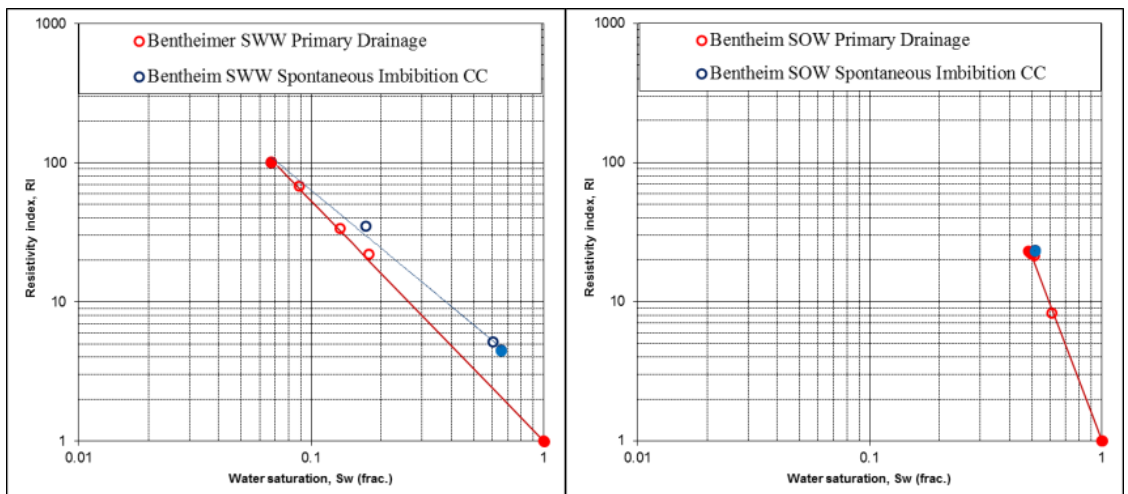

Figure 5. Bentheim Sandstone RI-S $S_{\mathrm{w}}$ transient data graphs, bold point are final equilibrium data at $S_{\mathrm{wi}}$ at $\mathrm{Pc}=5$ bar and $\mathrm{S}_{\mathrm{w}}$ after spontaneous imbibition process by counter current at $\mathrm{P}_{\mathrm{c}}=0$ bar. 

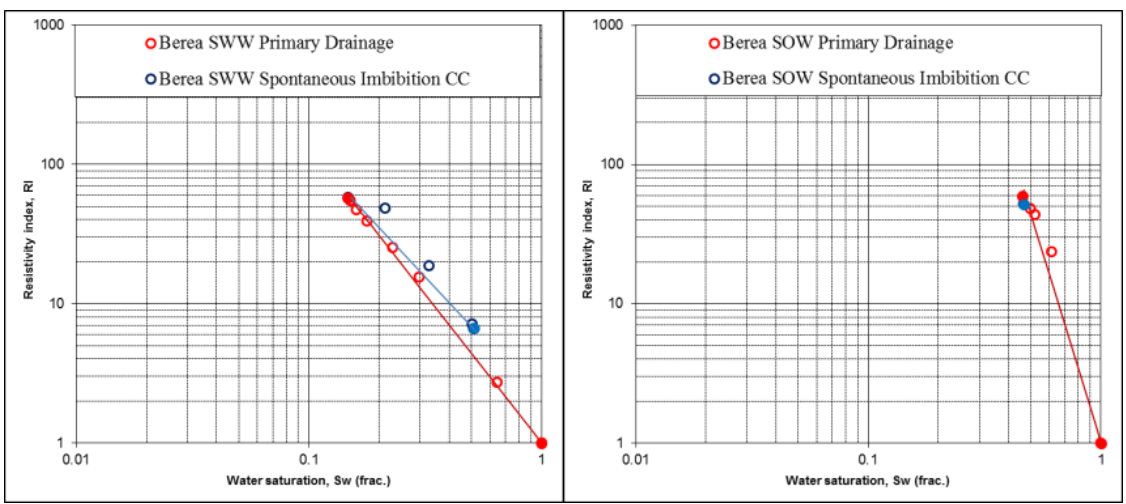

Figure 6. Berea Sandstone RI-S $S_{w}$ transient data graphs, bold point are final equilibrium data at $S_{w i}$ at $P_{c}=5$ bar and $S_{w}$ after spontaneous imbibition process by counter current at $\mathrm{P}_{\mathrm{c}}=0$ bar.
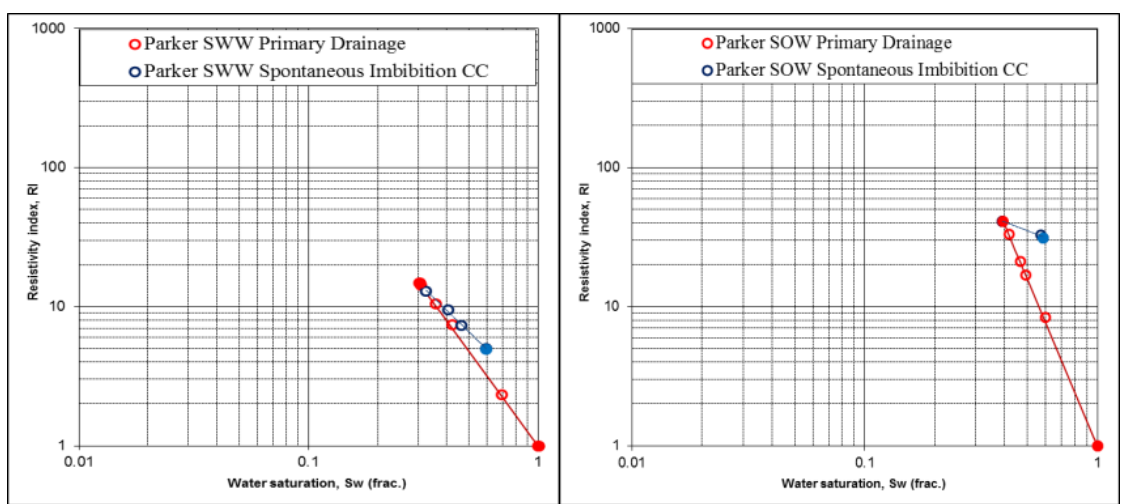

Figure 7. Parker Sandstone RI-S $S_{\mathrm{w}}$ transient data graphs, bold point are final equilibrium data at $\mathrm{S}_{\mathrm{wi}}$ at $\mathrm{P}_{\mathrm{c}}=5$ bar) and $\mathrm{S}_{\mathrm{w}}$ after spontaneous imbibition process by counter current at $\mathrm{P}_{\mathrm{c}}=0$ bar.
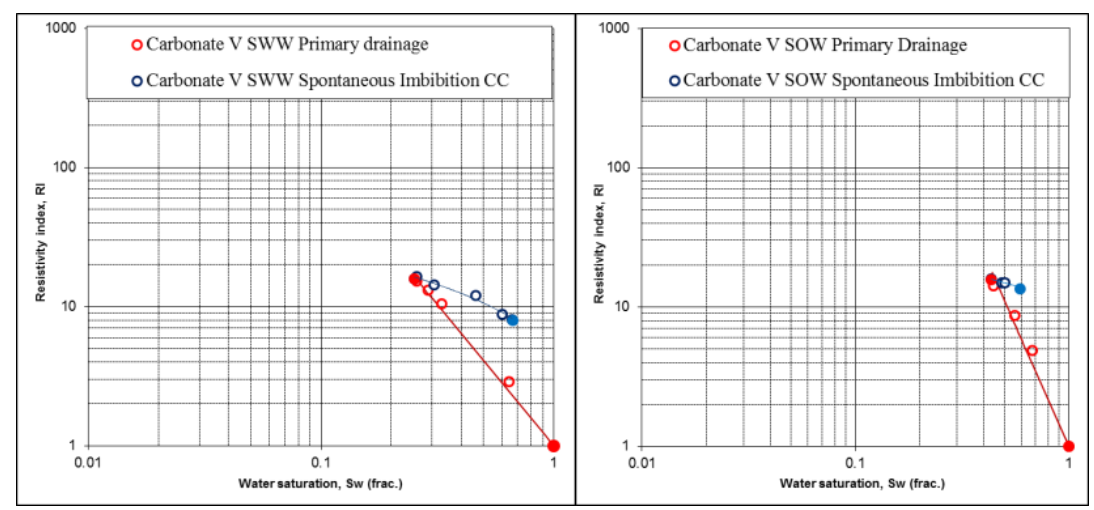

Figure 8. Carbonate V RI- $S_{w}$ transient data graphs, bold point are final equilibrium data at $S_{w i}$ at $P_{c}=5$ bar and $S_{w}$ after spontaneous imbibition process by counter current at $\mathrm{P}_{\mathrm{c}}=0$ bar.

\section{Conclusion}

We have demonstrated the feasibility of an improved approach to obtain valuable and robust saturation and RI data during Special Core Analysis capillary measurements by counter-current imbibition with a porous plate setup configuration.
1. We have proposed an efficient and robust method to perform capillary spontaneous imbibition at zero capillary pressure and resistivity measurements at representative overburden and temperature condition, using representative fluids.

2. A rapid evaluation of wettability at pseudoreservoir conditions can be performed with this methodology by use of saturation value and Archie 
saturation n-exponent transient and end point equilibrium data.

3. The proposed method is reliable for high permeability samples, whether poorly consolidated or stress sensitive, with the limitation that only single point saturation and RI results can be obtained. Resistivity data monitoring and evaluation improve water saturation control and understanding of capillary and rock/fluid equilibrium for both sandstone and carbonate lithologies. 4. The spontaneous imbibition by counter current technique is, based on our experience, much faster (approximately one week time) compared to the standard method for spontaneous imbibition cycle by porous plate, providing at least a 10 -fold time-saving benefit.

5. This methodology can be easily combined with existing procedures and workflows for capillary pressure by porous plate (drainage and spontaneous imbibition cycles) using dead crude oil and synthetic formation water, with only minor equipment/setup modification (double inlet lines) of the core holder upper end stem required.

6. Standard spontaneous imbibition experiments by porous plate can still be performed; the capillary countercurrent imbibition step can be added at the last step of the spontaneous imbibition cycle, when capillary pressure is equal to zero to improve the imbibition process and obtain more reliable saturation and RI data.

7. OOIP (\%) results after capillary spontaneous imbibition cycle were in agreement with published data available for water wet Berea and Bentheim sandstones $[21,22]$.

The authors thank Jon Knut Ringen (Orec AS) for the original idea that initiated this research project, Karwan Rush (WFT Labs Norway) for the technical support, and the whole WFT Labs team that contributed to the paper during the project execution and review phase

\section{References}

1. Archie G.E.: Electrical resistivity $\log$ as an aid in determining some characteristics, Trans. AIME (1942) 146, pp 54-62.

[1] Amott E.: Observations relating the wettability of porous rocks, Trans. AIME, (1959) 216,156-162.

[2] W.G. Anderson: Wettability Literature Survey - Part 3: The effects of wettability on the electrical properties of porous media, Journal of Petroleum Technology, December 1986, 1371-1378.

[3] W.G. Anderson: Wettability Literature Survey - Part 4: Effects of wettability on capillary pressure, Journal of Petroleum Technology, December 1986, 1283-1300.

[4] Lenormand R., Eisenzimmer A. and Zarcone C.: A novel method for the determination of water/oil capillary pressure of mixed wettability samples, SCA 9322
[5] Jadhunandan,P.P and Morrow, N.R.: Effect of wettability on waterflood Recovery for Crude oil/Brine/Rock Systems, SPE 22597, first presented SPE Annual Conference in Dallas 1991 (SPERE, 10 (1), 40 (1995)).

[6] Xianmin Zhou,' N. R. Morrow, S. Ma: Interrelationship of wettability, initial water saturation, aging time, and oil recovery by spontaneous imbibition and waterflooding, SPE35436, 1995.

[7] Ma, S., Morrow, N.R. and Zhang, X.: Generalized scaling of spontaneous imbibition data for strongly water-wet systems, JPSE, 18, p. 165-178, 1997.

[8] Ma, S.M. et al.: Characterization of wettability from spontaneous imbibition measurements, J. Canadian Petroleum Technology. Special Edition 1999, volume 38, No 13 Paper 94-47.

[9] G. Q. Zhang, C-C Huang, G.J. Hirasaki: Interpretation of wettability in sandstones with NMR analysis, SCA 9921.

[10] A. K. Moss and X. D. Jing: Resistivity Index and capillary pressure characteristics of reservoir sandstones in different wettability conditions, SCA 9945.

[11] Kewen Li and Roland N. Horne: Characterization of spontaneous water Imbibition into gas-saturated rocks, SPE 62552, June 2000.

[12] Kewen Li and Roland N. Horne: Extracting capillary pressure and global mobility from spontaneous imbibition data in Oil-Water-rock systems, SPE 80553, April 2003.

[13] D. Potocki, M. Ding, Apostolos Kantzas: Carbonate rock wettability interpreted from capillary pressure and imbibition resistivity index analysis, SCA 200303.

[14] H. Tie and N. R. Morrow: Oil recovery by spontaneous imbibition before and after wettability alteration of three carbonate rocks by a moderately asphaltic crude oil, SCA 2005-11.

[15] B. Lalanne, G. Hamon, S. Peltier, A. Saint-Pierre: A case of large hysteresis on resistivity index values between drainage and imbibition phases, SCA 201003.

[16] Nina Loahardjo, W. Winoto, N. R. Morrow: Oil recovery from Bentheim sandstone by sequential water-flooding and spontaneous imbibition, SCA 2012-22.

[17] Martin A. Fernø, Åsmund Haugen, Geoffrey Mason, N. R. Morrow: Measurement of core properties using a new technique-two ends open spontaneous imbibition, SCA 2014- 006.

[18] M. A. Fernø, Å .Haugen, B. Brattekåsa, G. Mason and Norman R. Morrow: Quick and affordable SCAL spontaneous core analysis, SCA 2015-002.

[19] Douglas W. Ruth, Geoffrey Mason, Martin A. Fernø, Åsmund Haugen, N. R. Morrow, Rasoul Arabjamaloei: Numerical simulation of combined 
co-current/counter-current spontaneous imbibition, SCA 2015- 003.

[20] Kelleher, H.A., Braun, E.M., Milligan, B.E., Glotzbach, R.C., Haugen, E., 2007: Wettability Restoration in Cores Contaminated by Fatty Acid Emulsifiers SCA2007-03.

[21] Buckley, J.S., Morrow, N. R., 2006: Wettability and Prediction of Oil Recovery from Reservoirs Developed with Modern Drilling and Completion Fluids, Report for the United States Department of Energy (DOE), BC-15164. 